\title{
Assessment of Startup Fuel Options for a Test or Demonstration Fast Reactor
}

Fuel Cycle Research \& Development

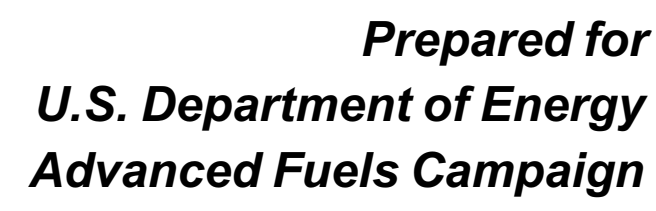

L. C. Walters, S. L. Hayes, and W. J. Carmack

September 2015 


\section{DISCLAIMER}

This information was prepared as an account of work sponsored by an agency of the U.S. Government. Neither the U.S. Government nor any agency thereof, nor any of their employees, makes any warranty, expressed or implied, or assumes any legal liability or responsibility for the accuracy, completeness, or usefulness, of any information, apparatus, product, or process disclosed, or represents that its use would not infringe privately owned rights. References herein to any specific commercial product, process, or service by trade name, trade mark, manufacturer, or otherwise, does not necessarily constitute or imply its endorsement, recommendation, or favoring by the U.S. Government or any agency thereof. The views and opinions of authors expressed herein do not necessarily state or reflect those of the U.S. Government or any agency thereof. 


\section{EXECUTIVE SUMMARY}

This document explores startup fuel options for a proposed test/demonstration fast reactor. The fuel options considered are the metallic fuels $\mathrm{U}-\mathrm{Zr}$ and $\mathrm{U}-\mathrm{Pu}-\mathrm{Zr}$ and the ceramic fuels $\mathrm{UO}_{2}$ and $\mathrm{UO}_{2}-\mathrm{PuO}_{2}$ (MOX). Attributes of the candidate fuel choices considered were feedstock availability, fabrication feasibility, rough order of magnitude cost and schedule, and the existing irradiation performance database.

The reactor-grade plutonium bearing fuels ( $\mathrm{U}-\mathrm{Pu}-\mathrm{Zr}$ and $\mathrm{MOX})$ were eliminated from consideration as the initial startup fuels because the availability and isotopics of domestic plutonium feedstock is uncertain. There are international sources of reactor grade plutonium feedstock but isotopics and availability are also uncertain. Weapons grade plutonium is the only possible source of $\mathrm{Pu}$ feedstock in sufficient quantities needed to fuel a startup core. Currently, the available U.S. source of (excess) weapons-grade plutonium is designated for irradiation in commercial light water reactors (LWR) to a level that would preclude diversion. Weapons-grade plutonium also contains a significant concentration of gallium. Gallium presents a potential issue for both the fabrication of MOX fuel as well as possible performance issues for metallic fuel. Also, the construction of a fuel fabrication line for plutonium fuels, with or without a line to remove gallium, is expected to be considerably more expensive than for uranium fuels. In the case of U-Pu-Zr, a relatively small number of fuel pins have been irradiated to high burnup, and in no case has a full assembly been irradiated to high burnup without disassembly and re-constitution. For MOX fuel, the irradiation database from the Fast Flux Test Facility (FFTF) is extensive. If a significant source of either weapons-grade or reactor-grade $\mathrm{Pu}$ became available (i.e., from an international source), a startup core based on $\mathrm{Pu}$ could be reconsidered.

The use of the metallic fuel $\mathrm{U}-\mathrm{Zr}$ and the ceramic fuel $\mathrm{UO}_{2}$ will both require enriched uranium, likely up to $20 \%$ U-235. It is uncertain whether the defense establishment can supply the required enriched uranium. It may be necessary to acquire the enriched uranium from a commercial vendor. Commercial LWR fuel vendors are currently licensed to enrich up to 5-6\% U-235, and would thus need to re-license to the higher enrichment level to be viable suppliers. Two commercial vendors of test reactor fuel in the United States are currently licensed for uranium enrichments greater than 20\%, BWX Technologies in Lynchburg, VA, and Nuclear Fuel Services in Erwin, TN. Neither of these two vendors are licensed to handle plutonium at present. Currently, handling and processing plutonium bearing fuels can only be accomplished in the DOE national laboratory system, with Idaho National Laboratory and Los Alamos National Laboratory being the primary establishments handling and fabricating significant quantities of fuels containing plutonium.

The question of U-235 feedstock needs to be pursued further with government and potential vendor authorities. The preferred source of U-235 would be from defense establishment feedstock.

For both $\mathrm{U}-\mathrm{Zr}$ and $\mathrm{UO}_{2}$, the fabrication experience is extensive. The $\mathrm{U}-\mathrm{Zr}$ fabrication capability that resided at the EBR-II site, now Idaho National Laboratory (INL) produced over 100,000 fuel pins that performed successfully in EBR-II. For $\mathrm{UO}_{2}$, most of the fabrication expertise and experience resides in the fabrication of $\mathrm{UO}_{2}$ fuels for LWR. However, a number of solid and annular $\mathrm{UO}_{2}$ fuel pins were fabricated and irradiated in FFTF.

The cost and schedule for either the $\mathrm{U}-\mathrm{Zr}$ or $\mathrm{UO}_{2}$ fabrication capability are comparable. The logical choice for the U-Zr fabrication facility is the INL, based upon past experience and existing expertise. The location selection for $\mathrm{UO}_{2}$ fabrication is not as clear as with metallic fuel fabrication, and commercial fabrication should probably be considered. 
The irradiation database for $\mathrm{U}-\mathrm{Zr}$ is extensive owing to a long history of use as a driver fuel for EBR-II, with significant, subassembly-scale demonstration in FFTF as well. The off-normal database for U-Zr fuel is also well established. For $\mathrm{UO}_{2}$, the situation is somewhat different. Minimal irradiation experience for fast reactor use of $\mathrm{UO}_{2}$ exists in the United States. However, internationally the use of $\mathrm{UO}_{2}$ in fast reactors is extensive. For example, $\mathrm{BN}-350$ used $\mathrm{UO}_{2}$ as its driver fuel throughout its lifetime (1974-1996), and BN-600 has used $\mathrm{UO}_{2}$ as its driver fuel from 1982 to the present. In addition, LWR experience with $\mathrm{UO}_{2}$ fuel carries over to some extent to its use in fast reactors. Thus, the licensing case could likely be made for either fuel.

Another important argument for the location and mission of the fuel fabrication capability is that fuel fabrication should be considered an integral component of the test/demonstration fast reactor. This argument follows from the 30 year experience gained with the operation of EBR-II. The composition of the driver fuel was changed several times during the operational life of the test/demonstration fast reactor, EBR-II, beginning first with U-5Fs and ending with U-10Zr. The cladding and duct material compositions were also changed several times beginning with 304SS, progressively changing to $316 \mathrm{SS}$, and finally ending with HT9. These changes constituted a part of the "demonstration" mission of the reactor. While these whole-core changes were taking place, a multitude of experiments were conducted on new fuels and materials, and these constituted the "test" mission of the reactor.

The "test/demonstration" mission of EBR-II was only possible because of the flexibility of the fuel fabrication line dedicated to supplying driver fuel for the reactor. There was never a large inventory of fuel ahead of reactor requirements, such that any major change in fuel design or composition did not result in a loss of inventory. Because of this flexibility, a change could be deployed rapidly. This could only be accomplished with a dedicated fabrication line available to serve as an integral part of the test reactor mission. Thus, it seems appropriate that the fabrication line associated with a new test/demonstration fast reactor be collocated with the reactor at a national laboratory. 


\section{CONTENTS}

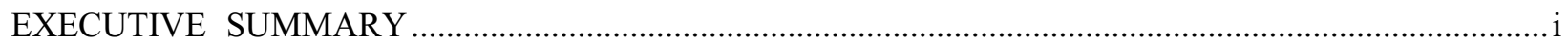

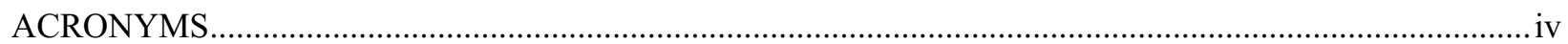

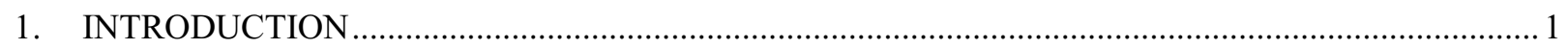

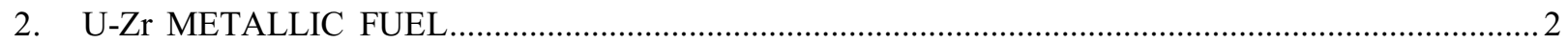

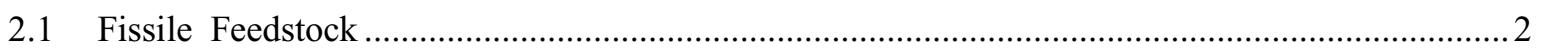

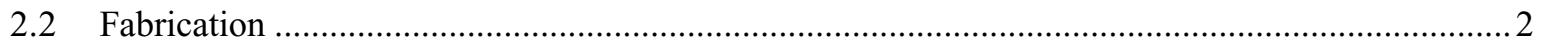

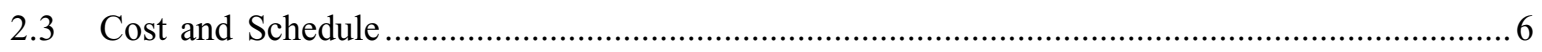

2.4 Performance Characteristics of U-Zr Metallic Fuel …..........................................................

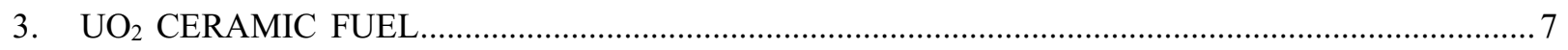

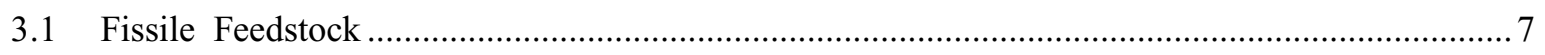

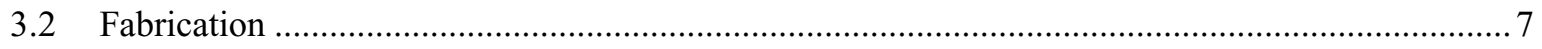

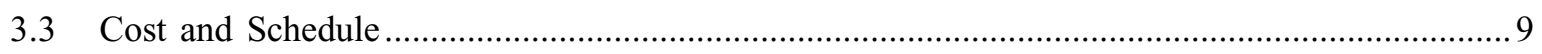

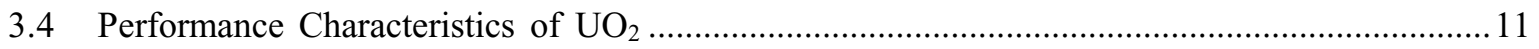

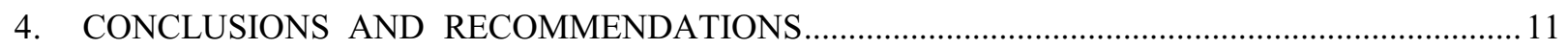

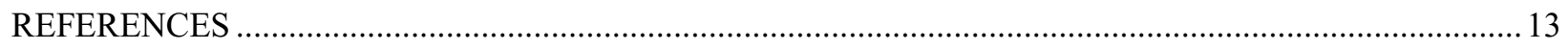

\section{FIGURES}

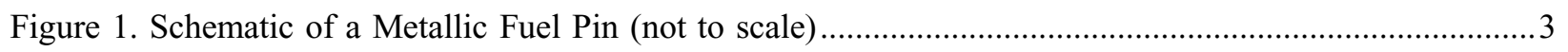

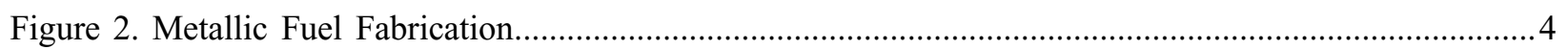

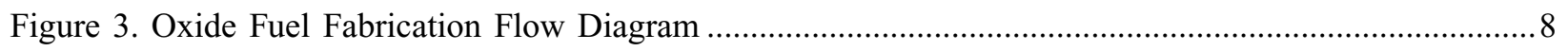

TABLES

Table 1. Design and Construction Schedule. .10 


\section{ACRONYMS}

$\begin{array}{ll}\text { ABR } & \text { Advanced Burner Reactor } \\ \text { DOE } & \text { Department of Energy } \\ \text { EBR-II } & \text { Experimental Breeder Reactor-II } \\ \text { FFTF } & \text { Fast Flux Test Facility } \\ \text { FMF } & \text { Fuel Manufacturing Facility } \\ \text { Fs } & \text { fissium (an alloy of Mo, Ru, Rh, Pd, Zr, and Nb) } \\ \text { HEU } & \text { highly enriched uranium } \\ \text { INL } & \text { Idaho National Laboratory } \\ \text { LEU } & \text { low enriched uranium } \\ \text { LWR } & \text { light water reactor } \\ \text { MCA } & \text { Materials Control and } \mathrm{Accountability} \\ \text { MOX } & \left.\text { mixed oxide (i.e., UO } \mathrm{U}_{2}-\mathrm{PuO}_{2}\right) \\ \text { SWU } & \text { Separate Work Unit } \\ \text { TIG } & \text { Tungsten Inert Gas } \\ \text { TREAT } & \text { Transient Reactor Test }(\mathrm{Facility}) \\ \text { US } & \text { United States }\end{array}$




\section{Assessment of Startup Fuel Options for a Test/Demonstration Fast Reactor 1. INTRODUCTION}

This report explores the feasibility of fuel options for a proposed test/demonstration fast reactor. The feasibility issues will be separated into four categories.

1. Feedstock: The fissile feedstock could be plutonium or enriched uranium. It is assumed that in today's political environment the concentration of plutonium or enriched uranium will be less than that required for weapons production. For uranium, the international standard is less than $20 \%$ U-235. For plutonium, the concentration will be somewhat less. Excess weapons-grade plutonium and enriched uranium may be available from the defense complex. However, at present the US inventory of excess weapons-grade plutonium is designated for irradiation in commercial light water reactors (LWR) to a level that would preclude its attractiveness for diversion. Weapons-grade plutonium also contains a significant concentration of gallium. Gallium presents a problem for both the fabrication of MOX fuel as well as possible performance issues for metallic fuel. The available enriched uranium from the defense complex is limited, with the competition being military applications as well as the conversion of highly enriched research and test reactors. Commercial enrichment plants are currently licensed to produce low enriched uranium to $5-6 \%$ and would require additional licensing effort to enrich further. Thus, the procurement of fissile feedstock is an important issue that will be explored further in this report.

2. Fabrication: Fabrication capability for fast reactor fuels no longer exists in the United States. Commercial LWR plants use $\mathrm{UO}_{2}$ fuel; thus, the fabrication technology for that fuel is quite mature. That technology could readily be extended to the fabrication of $\mathrm{UO}_{2}$ fuel or MOX fast reactor fuel. ${ }^{[1]}$ Fabrication of fast reactor metallic fuel was last accomplished at INL to fuel EBR-II and a partial fuel loading of FFTF. The technology for metallic fuel fabrication is proven and well documented. ${ }^{[2,3]}$ However, a significant scale up of the technology may be required to fuel a reactor that is significantly larger than EBR-II.

3. Cost and Schedule: Depending upon the option chosen, the cost and schedule could vary dramatically. A fuel fabrication line designed to fabricate either mixed oxide or plutonium alloy metallic fuel would be significantly more expensive than a line designed to fabricate $\mathrm{UO}_{2}$ or enriched uranium metallic fuel. All operations for plutonium alloy fuel would necessarily be glovebox operations with a significant escalation of cost and schedule, as experienced with the construction of the MOX plant at Savannah River National Laboratory.

The cost of $20 \%$ enriched uranium from a commercial supplier is approximately eight times more expensive than the cost of uranium enriched to $5 \%$. Furthermore, all the pilot-scale fabrication equipment for metallic fuel has been dismantled. A new higher capacity fabrication line for metallic fuel would need to be built. Similarly, the LWR fabrication technology for $\mathrm{UO}_{2}$ fuel would need to be adapted to the fabrication of fast reactor fuel.

4. Reactor Core Design: The reactor designers would ultimately decide on the driver fuel for a test/demonstration fast reactor. The decision will likely be a compromise based on availability of fissile feedstock, capability to fabricate the fuel, the cost and schedule of the fuel supply, and the desired performance characteristics of the fuel. In addition, anticipated licensing issues may be a factor for the choice of the driver fuel. 
The fuel options include two metallic fuel options (U-Zr and U-Pu-Zr) and two ceramic fuel options $\left(\mathrm{UO}_{2}\right.$ and MOX). For a test/demonstration fast reactor, plutonium-bearing fuels should be viewed as the startup-driver fuel options with a more arduous path to success. First, the source of excess weapons-grade plutonium feedstock is uncertain. Second, the gallium question exists for both MOX and U-Pu-Zr, although the concerns are different for the two fuel systems. For MOX, gallium removal seems important for good quality pellets, and the removal of gallium would be expensive. For U-Pu-Zr, preliminary data suggests that gallium can be tolerated, but there is likely not enough irradiation performance data to convince licensing authorities. Third, although U-Pu-Zr irradiation data exists for hundreds of experimental pins, including multiple subassemblies irradiated in EBR-II and FFTF (without gallium), no plutonium-bearing metallic fuel has ever been used as a driver fuel for a fast reactor; thus, there is no proven track record in convincing licensing authorities for whole core start-up and operation with a U-Pu$\mathrm{Zr}$ driver fuel ${ }^{\mathrm{a}}$. Finally, plutonium fabrication lines would be relatively more costly, and require a much longer schedule for completion, than uranium fabrication lines. (Certainly, small $\mathrm{Pu}$ or minor actinide fuel fabrication lines for test assemblies would be appropriate.) Therefore, $\mathrm{U}-\mathrm{Zr}$ or $\mathrm{UO}_{2}$ would appear to be the most straightforward options, providing there is access to nominally $20 \%$ enriched uranium feedstock and reactor performance based on an LEU fuel is acceptable. The $\mathrm{U}-\mathrm{Zr}$ and $\mathrm{UO}_{2}$ fuel options will be explored in the remainder of the report for availability of fissile feedstock, fabrication capability, cost and schedule, and irradiation performance characteristics.

\section{U-Zr METALLIC FUEL}

\subsection{Fissile Feedstock}

Two possible sources exist for enriched uranium. It is assumed that US policy will dictate that the maximum enrichment will be nominally $20 \% \mathrm{U}-235$. If the enriched uranium is available from the defense complex, as it was for the fueling of EBR-II, where highly enriched uranium (HEU) was downblended, then the cost would be minimal. However, if the enriched uranium must be procured from a commercial supplier, then the cost would be significant. For example, the cost for $20 \%$ enriched uranium to fuel a reactor core containing $10 \mathrm{MT}$ of fuel would be approximately $\$ 80 \mathrm{M}$. This assumes that a commercial vendor would obtain a license to increase their enrichment level from 5-6\% to $20 \%$ (and does not include their costs for doing so). This issue requires interaction with commercial enrichment vendors to determine if a re-license to a higher enrichment is feasible.

\subsection{Fabrication}

Metallic fuel was the driver fuel used in EBR-II throughout its entire 30 year life. The original fuel was a high smear density U-5Fs alloy that evolved to the final driver fuel used in EBR-II, a 75\% smear density U-10Zr fuel. More than 100,000 driver fuel pins were irradiated in EBR-II as well as a partial core loading in FFTF. In the early life of EBR-II, the fabrication technology was successfully transferred to two vendors, Aerojet General and Atomic International. For most of the life of EBR-II, and the metallic fuel supplied for FFTF, the fabrication of the fuel was accomplished at the Argonne-West site in Idaho (now part of the INL). It was demonstrated that the capacity of the Fuel Manufacturing Facility in Idaho was sufficient to fuel FFTF, which was a $400 \mathrm{MW}_{\text {th }}$ reactor.

The metallic fuel fabrication technology has been well documented in the literature. ${ }^{[2]}$ The fabrication method must meet the following requirements. With reference to Figure 1, the fuel slug radial dimensions must be such that the fuel slug occupies no more than $75 \%$ of the area inside the cladding inside diameter (i.e., $75 \%$ smear density). The surface condition of the fuel slug is not critical in so far as the average diameter meets the requirement of $75 \%$ smear density or less. After the fuel slug is cast, there

\footnotetext{
${ }^{a}$ This is not to suggest that a strong case for a U-Pu-Zr driver fuel cannot be made to a regulator; indeed, the authors believe it could be. It is merely to point out that it would be a first of a kind effort that would introduce additional cost and uncertainty.
} 
is no need for surface preparation. The alloyed composition must exist in a homogenous state in the fuel slug. The sodium bond provides a necessary heat transfer path during the initial phase of irradiation. The integrity of the sodium bond is such that no significant gaps exist between the fuel slug and cladding. The plenum above the fuel slug is sized to accommodate fission gas release and keep the internal pin pressure low enough that the cladding is not significantly stressed. The top and bottom closure of the cladding must be welded in such a fashion that the risk of weld failure is extremely low.

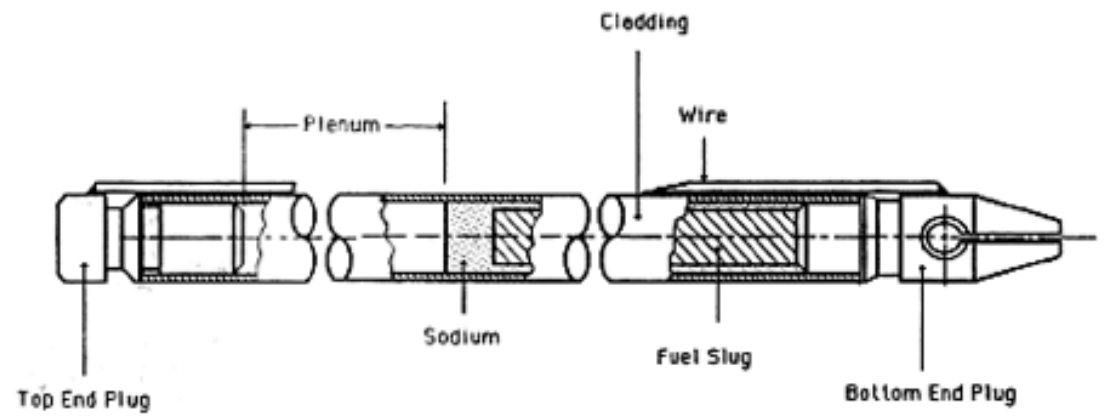

Figure 1. Schematic of a Metallic Fuel Pin (not to scale).

The following method can be utilized for the fabrication of fuel with unirradiated uranium alloyed with additional elements, such as zirconium. This fuel can be fabricated primarily with the use of hoods and a glovebox. For fuel that contains plutonium, virtually all operations must be conducted in gloveboxes. For reprocessed metallic fuel, the operations must be performed in a hot cell environment.

The fabrication technology is described in three areas: (1) the equipment necessary to fabricate the fuel; (2) the analytical support that provides the criticality safety requirements, the analyses necessary to track the special nuclear material balances, and the system for providing identification and tracking of individual fuel pins; and (3) the procedures and training necessary for the safe and reliable operation of the fabrication line.

Figure 2 shows the process flow diagram for the fabrication of metallic nuclear fuel. The first step is the preparation of the charge for the casting furnace. For the fuels of recent interest, the charge would consist of U-Zr or U-Pu-Zr put in a graphite crucible that had been coated with yittria. The crucibles are reuseable for several castings. The graphite crucible resides in an induction casting furnace. The induction coil of the furnace has at least two frequencies. The high frequency couples with the crucible, while the low frequency couples with the melt for stirring purposes.

The melt is brought to temperature with enough super heat to ensure that the viscosity of the melt will result in the adequate flow of the liquid metal. The heating of the melt is done under an inert (argon) atmosphere. After adequate stirring of the melt the furnace is evacuated. A pallet of Vycor molds, coated with a zirconia wash, are positioned above the liquid metal. The ends of the molds are inserted into the liquid metal and the furnace is rapidly pressurized. In an instant, the molds are filled with liquid metal that immediately solidifies.

The critical parameters for the casting operation are the quality of the mold wash, the pressurization rate, and the total pressure. The injection casting technique has been chosen because it is robust, repeatable, compact and readily adaptable to glovebox or even hot cell operations.

After the mold pallet is cooled, it is removed from the casting furnace. Vycor glass molds are broken away from the fuel slugs, and the fuel slugs are cut to length and may be radiographed to inspect for the existence of internal voids (although a tight specification on fuel slug mass may be sufficient to rule out 
the existence of any significant sized voids). The average diameter of the fuel slugs are measured with an air gage.

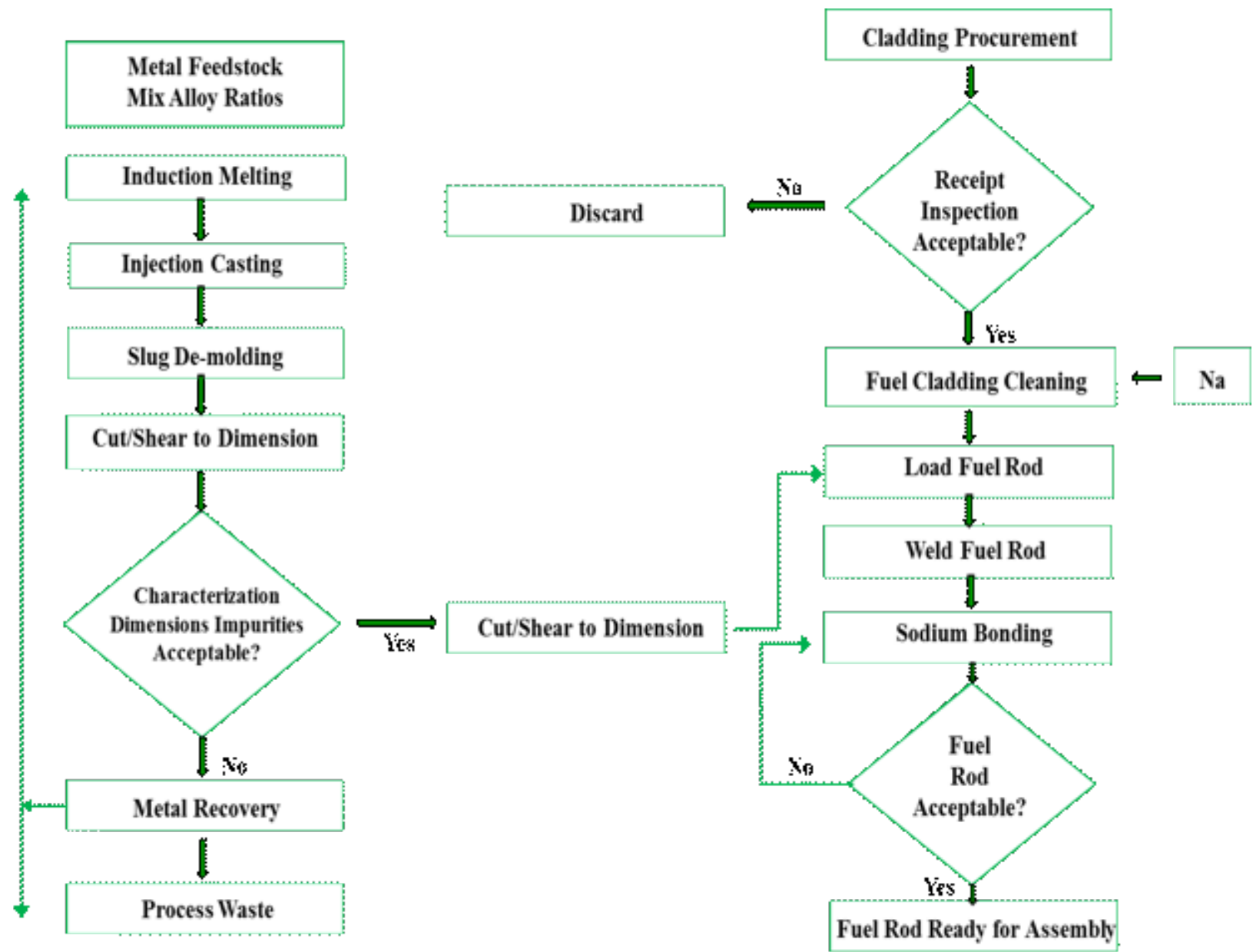

Figure 2. Metallic Fuel Fabrication Flow Diagram.

The cropped ends of the fuel slugs, along with the residual heal in the graphite crucible, are stored and can be recycled into future castings. The broken glass shards are stored because they contain small amounts of fissile material that must be either recovered later or disposed of as waste. At least one fuel slug from each casting batch is set aside for chemical analysis to verify fuel composition and homogeneity are within specification.

The fuel slugs are transferred to an inert atmosphere glovebox (typically argon, but usually with a helium concentration that is adequate to allow for leak checking of the finished fuel pin). Inside the glovebox, a furnace holds a number of cladding jackets ${ }^{\mathrm{b}}$ that contain the quantity of sodium needed for bonding. The furnace is brought to a temperature so that the sodium is in the liquid state. A fuel slug is then inserted into each jacket, and a top end plug is welded to the cladding jacket. Each of the fuel pins is leak checked to ensure weld integrity.

The fuel pins are removed from the glovebox and transferred to a bonding furnace, which holds a number of fuel pins. The furnace is brought is a temperature of $500^{\circ} \mathrm{C}$. At this temperature the sodium will wet

\footnotetext{
b A cladding "jacket" is the designation for a cladding tube, with the bottom end plug (and possibly the spacer wire) already welded in place.
} 
the cladding and fuel slug. The fuel pins are either impacted or vibrated to remove any voids in the sodium bond.

After removal from the bonding furnace, the integrity of the sodium bond is ensured by one of two techniques. One technique involves eddy-current interrogation of the bond, and the second utilizes radiography to determine sodium height in the jacket. At this stage, the completed fuel pins are ready for fabrication of the fuel assembly for reactor insertion.

Should this technology be adopted for the proposed test/demonstration fast reactor driver fuel, several possible improvements over the historical process could be implemented. All the operations described above were conducted with 1960's technology. Application of advanced manufacturing techniques, such as robotic operations, would likely enhance the quality and efficiency of the fabrication operations. The use of reusable instead of graphite crucibles would reduce waste. An automated means of removing the Vycor glass molds would also enhance the process. The glass shards contain a significant quantity of fuel particles, and a process needs to be developed to recover them. Finally, the further development of bottom-pour castings instead of counter gravity injection castings could eliminate both the sizeable heal remaining after injection casting as well as the use of Vycor molds and their associated waste stream.

Several supply lines must be established for the consumable materials used in the fuel fabrication. For example, the casting furnace requires Vycor molds, graphite crucibles, and zirconia and yittria wash, as well as the fuel materials (i.e., uranium, zirconium, and perhaps plutonium). A supplier must be identified for the jacket components, which include the cladding tube, end fittings, and the wire wrap. Lastly, all components for the assembly, which includes the hex duct, reflector blocks, and upper and lower end fitting, must be fabricated by a certified vendor.

A fabrication facility operating on enriched uranium feedstock will require a rigorous criticality safety regime, a safeguards regime, and a quality control regime. The facility will be an actively guarded, controlled access space, and fissile-containing inventories of in-process items and finished products will have to be stored in vaults. The facility workspaces and vaults will be subdivided into administrative Material Balance Areas for criticality and safeguards control of enriched uranium inventories.

These interdependent material control regimes will rely on a Materials Control and Accountancy (MCA) software system tightly integrated with the operating staff actions on the floor. The MCA system will maintain real-time inventories of fissile-containing materials in each of the material balance areas and vaults, and it will track the movements of fissile-containing "items" from one balance area to another. The "items" (e.g., fuel feedstock, cast fuel slugs, casting heals and end croppings, fuel pins, fuel assemblies, and fuel assembly clusters) will each be assigned a unique identifying tag number, and the MCA software will maintain its records of heavy metal mass, composition and location organized by item identification number. As cast slug items are incorporated into pins, fuel pin items are incorporated into assemblies, and fuel assembly items are collected into clusters, the MCA software will keep track of the resulting masses and compositions of the newly created items.

Physical measurements on fissile containing materials will be made as part of the fuel slug casting operations. Mass spectroscopy will determine enrichment, and wet chemistry will determine alloying element content. Weights and dimensions will be by direct measurement. However, once the slugs are incorporated into pins, direct measurements (except for weight) become impossible, so the material control thereafter depends on administrative procedures that rely on MCA records.

Proposed movements of items will first be checked for compliance with criticality safety constraints using the MCA database. Product quality control records will be generated using the MCA database. Safeguards inventory records will be based on the MCA database, and periodic physical inventories conducted on the 
mass balance areas will be used to over-check that the MCA records remain always consistent with the physical inventories.

An important aspect of a fuel fabrication facility is the training of all operators according to procedures written by the engineers who designed the equipment and provide the analytical support. Safety is the paramount consideration. Procedures and operator training to prevent criticality accidents involves both the education of the operators and training according to procedures. Further, several operations involve high temperature, high pressure, and potentially pyrophoric materials. A training department is necessary to ensure that all operators are qualified to perform work safely.

Quality assurance of nuclear fuel must be guaranteed. Quality assurance principles are embedded in all procedures. Further, a quality assurance department oversees and verifies the quality of the final product. A radiological safety department oversees all daily operations to ensure minimal radiation exposure to workers. The following are a few of the qualifications that operators must achieve.

- Fuel Handler

- Criticality Safety

- Radiation Safety

- Quality Assurance

- Materials Control and Accountability

- Specific Equipment Qualification

- Glovebox Safety Operation

- Emergency Response

\subsection{Cost and Schedule}

Should the test/demonstration fast reactor be limited in size to approximately $300 \mathrm{MW}_{\text {th }}$ or less, the fabrication of a metallic driver fuel could be accomplished at the INL site in much the same fashion as the fuel for EBR-II and FFTF were fabricated. Although the previous equipment used for metallic fuel fabrication has been discarded, the engineering design documents are still available. The support services, such as analytical chemistry, radiological control, safety, and security, and engineering expertise, also exist on site. The Fuel Manufacturing Facility (FMF), located at the Materials and Fuels Complex and used previously to fabricate the driver fuel for EBR-II, has a new mission and may not be available; thus, a new facility would need to be constructed. From past experience, at least two years would be required to restore fuel fabrication at INL.

The cost for this fabrication restoration at INL was previously estimated to be $\$ 116 \mathrm{M}$ for a metallic fuel fabrication facility to fabricate U-Pu-Zr metallic fuel. ${ }^{[4]}$ This estimate was made in 2007 by the architectural engineering consortium headed by ANNA, Inc., which included Burns \& Roe Enterprises. Vista Engineering Technologies, LLC, was contracted for the pre-conceptual design and cost estimates. With INL participation, ANNA, Inc. developed the technical and functional requirements for a fabrication facility, a facility Options Analysis (i.e., annex to the existing FMF vs. a new, stand-alone facility, integrated vs. separate gallium removal facility, etc.), a pre-conceptual design for the preferred facility option, and cost estimates for the facility construction and process equipment acquisition.

The cost for a U-Zr fuel fabrication facility should be significantly less, since the gallium removal line would be unnecessary, and most of the operations for U-Zr fabrication could be conducted without the use of gloveboxes. 
The cost of $20 \%$ enriched uranium is significant if procured from a commercial supplier. Three major costs are associated with the procurement of enriched uranium: the $\mathrm{U}_{3} \mathrm{O}_{8}$ feedstock, the conversion to $\mathrm{UF}_{6}$, and the Separate Work Unit (SWU) for enrichment. For 20\% enriched uranium, the cost is approximately $\$ 8 \mathrm{M} / \mathrm{MT}$.

\subsection{Performance Characteristics of U-Zr Metallic Fuel}

The steady-state and transient performance of metallic fuels is well documented. ${ }^{[5-9,13]}$ Perhaps the most beneficial characteristic of metallic fuel is the fact that the high thermal conductivity of metallic fuel allows cooler operation than other fuel types. However, it is in the inherent passive safety potential where metallic fuel is far superior to other fuel types. Due to low fuel operating temperatures, the stored Doppler reactivity at power is small, which is an important factor for achieving benign responses to severe accident conditions. ${ }^{[7]}$ Also, the fabrication of metallic fuel should also be considerably less expensive than a ceramic fuel. Finally, if the used fuel is to be recycled to recover the remaining enriched uranium and in-bred plutonium, the pyroprocess is well developed and demonstrated at INL for carrying out this operation.

A large number of in-reactor test assemblies for U-Zr over a wide range of operating conditions and cladding types have been conducted in EBR-II, FFTF, and the Transient Reactor Test (TREAT) Facility. These data are well documented in literature. A peer reviewed gap analysis concluded that sufficient data were available to license a U-10Zr core with $316 \mathrm{SS}$ cladding within the limitations of the operational database of 10 at.\% burnup and cladding temperatures below $590^{\circ} \mathrm{C} .{ }^{[10]}$

\section{3. $\mathrm{UO}_{2}$ CERAMIC FUEL}

\subsection{Fissile Feedstock}

The issues associated with the procurement of enriched uranium feedstock for a $\mathrm{UO}_{2}$ driver fuel are identical for those that exist for U-Zr metallic fuel.

\subsection{Fabrication}

$\mathrm{UO}_{2}$ fuel fabrication is essentially identical to MOX fuel fabrication. The MOX fuel fabrication process used in the United States is as follows. The general MOX fuel rod fabrication process is illustrated in Figure 3.

The MOX fuel fabrication process is derived from the processes used to fabricate fuel for LWRs in Europe. The process for fabrication of MOX fuel rods for fast reactors is expected to be similar. Anticipated differences are discussed in the descriptions below. This description is not meant to be allinclusive, but is representative of the scope of work associated with the fabrication processes.

Plutonium and uranium oxide feed material is required to meet rigorous specifications for isotopic vector, impurity content, particle size distribution, and residual moisture. The feedstock can include scrap material from previous runs, which is generally considered to improve the final product.

In the primary blend step, the plutonium oxide, uranium oxide, and scrap feed materials are initially blended. The feedstock is poured into a blender jar, and milling media may be added to enhance particle size requirements. During this operation, binders and pore formers may also be added. The primary blend step typically produces $\mathrm{MOX}$ with $20-30 \mathrm{wt} . \% \mathrm{PuO}_{2}$ blended powder with a fine particle size that is intimately mixed. 
In the secondary blend operation, another blender jar is filled with primary blend and additional $\mathrm{UO}_{2}$, then run on a Turbula ${ }^{\circledR}$ blender. The secondary blend step may not be required for a fast reactor MOX fuel with $20-30 \% \mathrm{PuO}_{2}$.

The blender jar is connected to the pellet press sieve, and the blend is sieved and transferred to the press feed hopper. Pellets are pressed using a hydraulic press that can press one or more pellets simultaneously. These green pellets are then placed on sintering boats and stored.

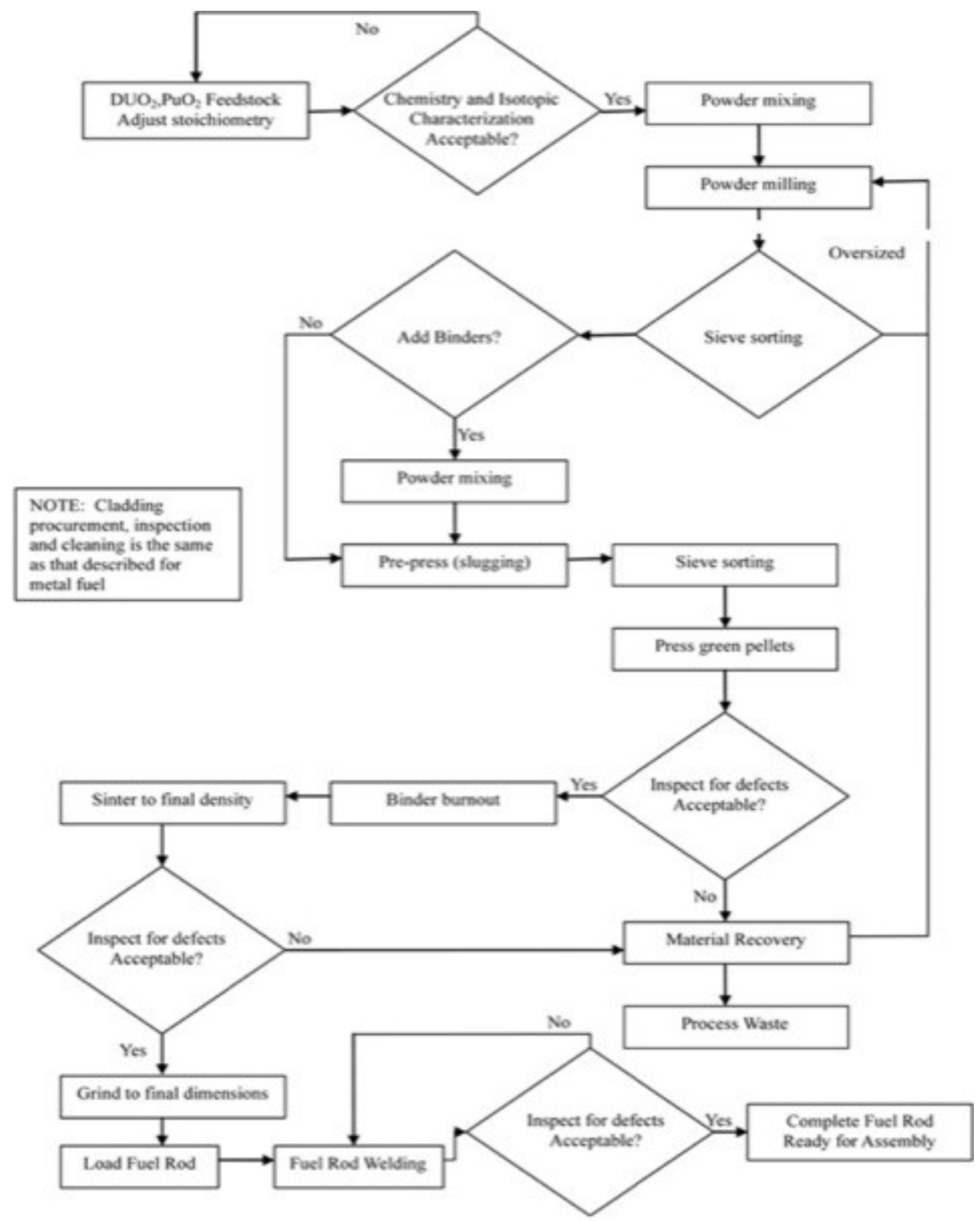

Figure 3. Oxide Fuel Fabrication Flow Diagram.

The sintering boats containing green pellets are moved from a green pellet storage glovebox and are loaded into a sintering furnace. The furnace operates as a batch process at a specified rate, resulting in a time-temperature sintering profile that yields dense pellets that meet specified requirements.

The pellets are placed in a grinder feed hopper and processed through a centerless grinder to obtain the specified final diameter. Pellet diameter is confirmed during the grinding process using a laser 
micrometer. Pellets are further inspected to ensure they meet physical specifications, then sorted (segregating any pellets that failed to meet specification).

Rejected pellets are collected in a crusher box. After collecting a sufficient quantity, a jaw crusher reduces them to a suitable particle size. This material can become part of the feed for future fuel pellets.

The sorted pellets are set for the column length needed for one fuel rod. The fuel rod subassembly (i.e., fuel rod cladding with its bottom end cap pre-welded into place) is slid through a hood enclosure at the end of the fuel rod fabrication glovebox and into the purge chamber.

The fuel pellet column is loaded into the fuel rod cladding. After decontaminating the rod, the spring and end cap are installed. The assembled fuel rod is slid into the welding compartment where the end cap is permanently welded into place using a rotary Tungsten Inert Gas (TIG) welder.

Following seal weld inspection and verification that decontamination requirements have been met, the fuel rod assembly is slid back through the welding compartment and out of the hood enclosure. The fuel rod is then inspected by radiography for weld integrity and gamma scanned (or radiographed) to verify proper fuel pellet location.

\subsection{Cost and Schedule}

In 2007, Los Alamos National Laboratory was tasked to look at the feasibility of producing a MOX fuel startup core for the Global Nuclear Energy Partnership Advanced Burner Reactor (ABR) at the Plutonium Facility (TA-55, PF-4). ${ }^{[1]}$ Merrick \& Company, an architectural and engineering firm, was contracted to perform the study. Merrick subcontracted to Smith Concepts \& Designs to perform the baseline process flow, capability design, and construction schedule estimate. Smith Concepts also performed an analysis for an annual MOX fabrication rate and costs. A second subcontractor, Q-Consulting, provided a construction cost estimate based on the design, build, and install schedule. The basis for the fuel capability design was traditional MOX fabrication to the FFTF MOX fuel specification. The study was based on several assumptions, namely, plutonium oxide feed powder meeting specification is supplied from an outside source and the work is performed in a Category I Nuclear Facility. Other considerations taken into account are worker As Low As Reasonably Achievable radiation exposure and laboratory ergonomic goals. This study specifically looked at the configuration and costs for one room and a portion of a second room in PF-4. Related infrastructure costs, such as vault operations, storage of fuel pins, packaging and transportation, etc., were not investigated in this study. In addition, the fabrication process ended with fuel pin assembly, but no fabrication of core assemblies. Some alternative processing techniques were identified during the feasibility study to increase production rates, but they would require further evaluation.

The facility layout to support the MOX fabrication and fuel pin assembly used the majority of two standard rooms in PF-4. The room configuration requires the larger equipment be placed in the middle of the room to accommodate the doublewide gloveboxes. This results in a somewhat inefficient process layout. If a doublewide room in PF-4 were utilized, this would support a more efficient process layout because there would be greater flexibility in placement of the doublewide gloveboxes. The study began with the research and development MOX fabrication process from PF-4, and then looked at incorporating fabrication techniques that support larger scale fabrication. Some of these alternative processing techniques would need to be evaluated before being incorporated into a construction design. This detailed analysis resulted in equipment and glovebox models, which were used to support the cost and schedule estimates.

Table 1 shows the design and construction schedule covering all the major steps to establish a capability, including engineering and design, equipment acquisition, facility preparation, glovebox installation, 
facility systems, installation qualification, authorization basis, and production set-up and qualification of the fuel fabrication line. The total schedule for these activities was 5.5 years for design and construction and 1.5 years for fabrication qualification. Engineering and design was 3 years in order to test out new concepts for streamlining the process and to develop a robust design. The schedule could be shortened by beginning to evaluate new concepts now with fuel development money. The construction phase, including installation and qualification, was 2.5 years. This assumed gloveboxes and equipment would be built and tested outside, then moved into PF-4 and connected to facility utilities. Authorization basis work is intermittent and ongoing from near the beginning of the project through the operational readiness assessment. MOX fabrication qualification was scheduled for 1.5 years.

Many of the schedule activities are overlapping and not in series. The conceptual design included equipment selection, material transport, and specific glovebox designs for the process. This generated detailed equipment lists which supported the schedule and cost analysis.

Table 1. Notional Fuel Fabrication Facility Design and Construction Schedule.

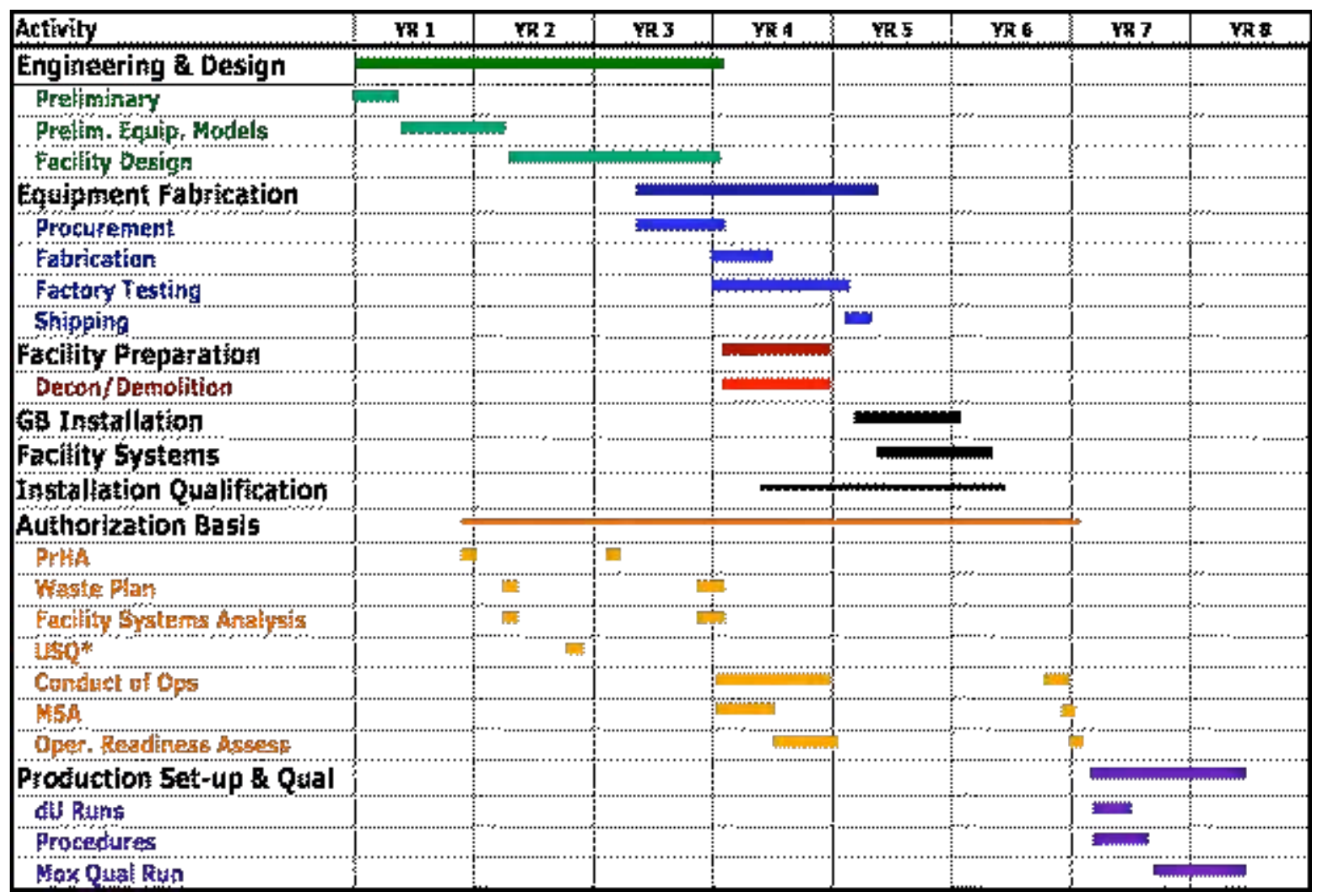

The cost estimate was based on the schedule and quotes from glovebox and equipment manufacturers. The cost estimate, based on FY07 dollars, included a 14\% escalation factor to coincide with the start of construction. The construction costs covered equipment fabrication through installation and qualification. The cost ranged from a low of $\$ 102 \mathrm{M}$ to a high of $\$ 168 \mathrm{M}$, with an accuracy of $-10 \%$ to $+40 \%$. Project cost contingency of $40 \%$ is included in these costs. This also included glovebox defueling and decommissioning costs, which are highly variable. MOX fabrication set-up and qualification were not covered in the cost analysis. Typically, programmatic operating funding is used for fabrication startup and qualification. An annual fuel fabrication rate was calculated for the feasibility study, because the core is undefined. This throughput study used the PF-4 workweek schedule of four 10-hour days per week, and 
assumed $70 \%$ plant availability. The fuel fabrication schedule has two fuel batches starting each day, with six completed per week. It takes five working days to produce a $10-\mathrm{kg}$ batch of fuel. The steady state process throughput analysis to produce pellets $\sim 0.5 \mathrm{~cm}$ in diameter and $0.6 \mathrm{~cm}$ long yielded an annual production rate of $2,000 \mathrm{~kg}(2 \mathrm{MT})$, equating to $\sim 50,000$ pellets/week or $\sim 1.8$ million pellets/year. The requirement for inspecting $100 \%$ of pellets was the rate limiting factor in production, followed closely by the centerless grinding capacity. Production costs were estimated at $\$ 15 \mathrm{M}$ annually.

\subsection{Performance Characteristics of $\mathrm{UO}_{2}$}

The US database for $\mathrm{UO}_{2}$ fast reactor fuel is somewhat limited, with only a few assemblies having been irradiated in FFTF. The Russian fast reactor BN-350 used $\mathrm{UO}_{2}$ fuel throughout its lifetime (1974-1996), and $\mathrm{BN}-600$ used $\mathrm{UO}_{2}$ fuel exclusively from 1982 onward. Their experience indicated that $\mathrm{UO}_{2}$ fuel is capable of reliable operation to a relatively high burnup. LWR reactors use $\mathrm{UO}_{2}$ fuel worldwide; although the operating temperatures are lower, much of the irradiation performance phenomena translate to the fast reactor fuel.

Worldwide, the irradiation database for MOX fuel is extensive and well documented. ${ }^{[12,13]}$ With FFTF and other international fast reactors, it has been demonstrated that MOX fuel is capable of reliable performance to relatively high burnup. The MOX experience is directly applicable to that for $\mathrm{UO}_{2}$. Thus, it is evident that an acceptable licensing case could be made for $\mathrm{UO}_{2}$ as a startup driver fuel in a fast reactor.

\section{CONCLUSIONS AND RECOMMENDATIONS}

Conclusions and recommendations from this assessment are as follows:

1. $\mathrm{U}-\mathrm{Zr}$ metallic fuel or $\mathrm{UO}_{2}$ ceramic fuel are the most straightforward options for startup fueling of a test/demonstration fast reactor in the near term (without identification of a suitable $\mathrm{Pu}$ feedstock). The existing performance database to support licensing is sufficient for both fuel types, and the necessary fabrication technologies are mature.

2. Both fuel types will likely be required to use uranium enriched to $20 \%$ or less ${ }^{\mathrm{c}}$. Commitment for the supply of $\sim 20 \%$ enriched uranium should be secured from either a government source or commercial vendor.

3. The test/demonstration fast reactor should capitalize on experience gained from the operation of EBR-II and FFTF. The fabrication line for either fuel type should be closely coupled to reactor operation. The inventory of driver fuel should only somewhat exceed reactor needs. This affords the flexibility to institute fuel design changes as necessary. During the life of EBR-II, design and cladding compositions were changed several times as part of its demonstration mission.

4. As part of the test/demonstration fast reactor mission, transuranic bearing fuels - whether they be MOX, U-Pu-Zr, minor actinide bearing fuels, or others - could be fabricated in smaller, dedicated pilot lines and make use of some of the same equipment from the $\mathrm{U}-\mathrm{Zr}$ or $\mathrm{UO}_{2}$ lines.

5. The choice of the fuel type (i.e., metallic or oxide) for the test/demonstration fast reactor should be made as soon as possible with the recognition that fabrication lines for either $\mathrm{U}-\mathrm{Zr}$ or $\mathrm{UO}_{2}$ do not currently exist in the US.

\footnotetext{
${ }^{\mathrm{c}}$ This assumes that acceptable reactor performance can be achieved with an LEU core, which remains to be determined.
} 
6. A specific study should be conducted to select a suitable fuel fabrication location and acquisition strategy that considers the current DOE laboratory and US nuclear industry capabilities and infrastructure. 


\section{REFERENCES}

1. D. Burkes, et al., (2009) "A US Perspective on Fast Reactor Fuel Fabrication Technology and Experience Part II: Ceramic Fuels," Journal of Nuclear Materials, Volume 393, pp 1-11.

2. Douglas E. Burkes, et.al. (2009) "A US perspective on fast reactor fuel fabrication technology and experience part I: Metal fuels and assembly design”, Journal Nuclear Materials, Volume 389, pp. 458-469.

3. W. Carmack, et al., (2009) "Metallic Fuels for Advanced Reactors," Journal of Nuclear Materials, Volume 392, pp 139-150.

4. D. Porter and M. Ebner, (2007) "Pre-Conceptual Design and Cost Estimate for an ABR Metal Fuel Fabrication Facility,” Rev 0, INL/EXT-07-13216, GNEP-ABR-Fuel-TD-RP-2007-000338, September 20, 2007.

5. G. L. Hofman and L. C. Walters (1994) "Metallic Fast Reactors Fuels", Nuclear Materials, Part 1, Chapter, 1, Volume 10A, VCH Germany.

6. G. L. Hofman, L. C. Walters, and T. H. Bauer (1997) "Metallic Fast Reactor Fuels", PII: S01491970(96)00005-4, Progress in Nuclear Energy, Volume 31, No. 1-2, pp. 83-110.

7. Yoon H. Chang (2007) "Technical Rationale for Metal Fuel in Fast Reactors", Nuclear Engineering and Technology, Volume 39 No. 3, pp. 161-170.

8. Douglas C. Crawford et.al. (2007) "An approach to fuel development and qualification”, Journal of Nuclear Materials, Volume 371, pp. 232-242.

9. W. J. Carmack et.al. (2009) "Metallic fuels for advanced reactors", Journal Nuclear Materials, Volume 392, pp. 139-150.

10. L. Walters, et al., (2011) "Sodium Fast Reactor Fuels and Materials: Research Needs" SAND REPORT, SAND2011-5299359, September 2011.

11. J. Carmack, K. Pasamehmetoglu (2008), "Assessment of Startup Fuel Options for the GNEP Advanced Burner Reactor (ABR),” Rev 0, INL/EXT-08-13773, GNEP-Fuel-Fuel-TD-RT-2008000049, February 2008.

12. R. Leggett, and L. Walters (1993) "Status of LMR Fuel Development in the United States of America," Journal of Nuclear Materials, Volume 00, pp. 1-10.

13. Douglas C. Crawford, Douglas L. Porter, and Steven L. Hayes (2007), "Fuels for sodium-cooled fast reactors: US perspective", Journal of Nuclear Materials, Volume 371, pp. 202-231. 